a year more, bringing the average salary to $£ 4,250$. The upper echelons of the hospital service will also receive 8 per cent but, just as the Prices and Incomes Board recently gave a greater proportional increase to junior university staff, the Review Body awards 14 per cent instead of 8 per cent to house officers, the lowest grade of the hospital service, who will now start at $£ 1,250$, increasing in three years to $£ 1,450$-an increase of $£ 150$ a year.

In an addendum, Lord Kindersley's committee says that the Prices and Incomes Board, in its recent report on academic pay scales, drew attention to the anomaly that university salaries have been referred to the board although the medical salaries have thus far escaped its attention. The Review Body says this situation is inherent in the acceptance of the recommendations of the royal commission on medical salaries which reported in 1957-and the Review Body goes on to say that its existence is justified by the need for a totally independent organization to scrutinize doctors' wages.

Meanwhile, there has been a chorus of protests about the way in which the University Grants Committee apparently intends to implement the PIB's recommendation that university teachers holding honorary consultancies should be paid on National Health Service consultant scales. After all, considerable sums of money are at stake. In a letter of December 23, 1968 , to the Principal of the University of London, the UGC suggested that clinical lecturers, senior lecturers and readers with consultancies should be translated to a point on the NHS scale nearest to their present salary and not by order of seniority. If this should mean a drop in salary, the teachers should remain at their present salary until their next increment falls due. This scheme has the merit of simplicity but it will create a host of new anomalies. First, the university pay scales vary significantly from university to university. Second, the NHS scales are usually better than the university scales and the Review Board's award has increased the difference (see table). As articles in the Lancet $(1,199$ and $254 ; 1969)$ in the past fortnight have pointed out, the UGC's recom. mendation entirely misses the spirit of the PIB's report, which was explicit enough - that those with consultancies should receive comparable pay irrespective of whether they work for a university or the NHS. Obviously the thing to do is to assimilate university clinical teachers on the NHS scale at a point which gives them the same salary as NHS consultants of the same seniority. It is inexplicable that the UGC should try to do otherwise.

\section{RADIO TELESCOPES}

\section{Straight Track for Cambridge}

THE widespread pruning of the British railway network has its advantages for the Mullard Radio Astronomy Observatory of Cambridge University. An axed section of the Cambridge-Bedford line is the northern boundary of the observatory's Lord's Bridge site, and runs in a straight line almost due east-west for about three miles. The track has proved to be just the site for the new three-mile telescope, a linear array of eight dish aerials for which the Science Research Council announced the go-ahead last week (Nature, 221, 515; 1969). Otherwise the observatory would have had to negotiate with neighbouring farmers for more land. Lord's Bridge station stands derelict, roughly in the middle of the stretch of line, and is to be the site of the control room of the new telescope.

At the Cavendish Laboratory last week, Professor Sir Martin Ryle, director of the observatory, eloquently outlined the scientific case for the telescope, which will take two years to build and will cost the SRC $£ 2 \cdot 1$ million. The gist of what he said is that the telescope will be primarily a mapping instrument, plotting radio sources with a resolution of one or two seconds of arc. This compares with the 20 seconds of are achieved by the present mapping telescope, the one-mile array. Professor Ryle described the situation which has arisen in astronomy with the discovery of a succession of quite unexpected sources, such as quasars and radio galaxies, requiring mechanisms which cannot be accounted for by physics and conditions which can never be reproduced in terrestrial laboratories. The

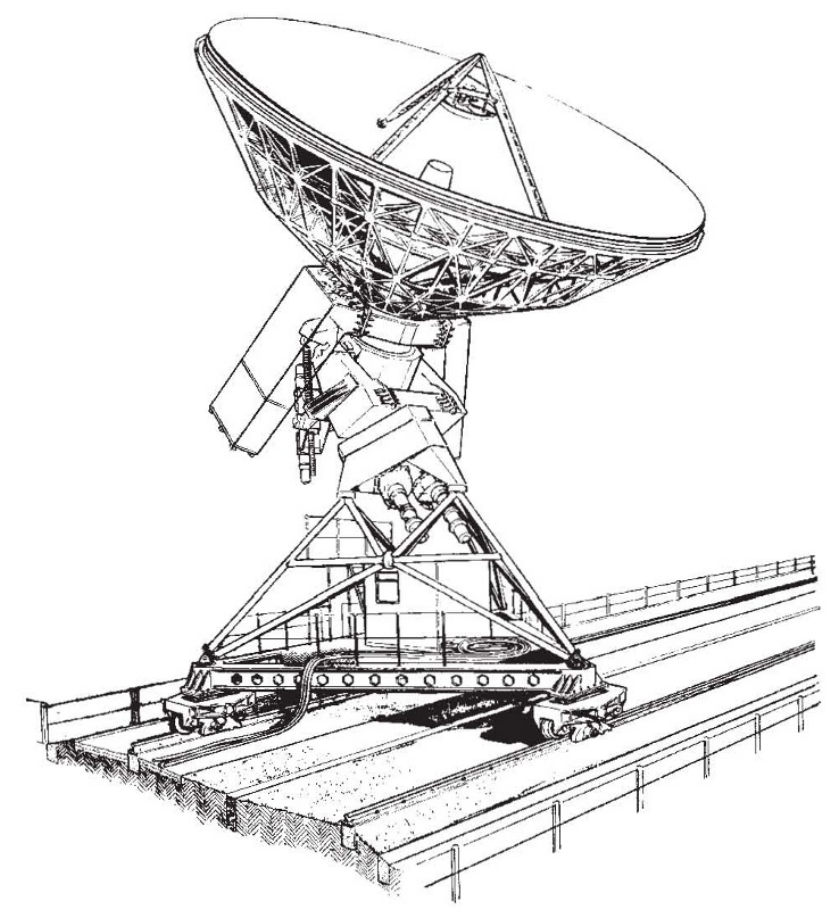

Traversable aerial for the three-mile telescope

hope is that detailed maps will throw some light on what is going on in the sourees. Cosmology should also benefit from a new mapping instrument one criticism of the source counts which have become a speciality at Cambridge is that they are hard to understand while the nature of the sources remains unknown. Mapping of supernovae remnants is also likely to receive high priority with the new telescope.

In its simplest form, the aperture synthesis technique which will simulate a three-mile dish requires two dish aerials whose separation can be varied by up to three miles. The rotation of the Earth means that, viewed from space, one aerial draws out an are relative to the other. By varying the separation up to three miles, successive ring elements of the dish are filled in. This is the principle of the one-mile telescope at Lord's Bridge, except that, to save time during the observations, three 60 foot dishes are spaced in a linear eastwest array. The east and centre aerials are fixed half 
a mile apart, while the third aerial runs on rails extending half a mile to the west of the centre aerial. Thus signals corresponding to two spacings can be recorded at the same time, and all spacings up to one mile are possible. As well as the saving in time, this layout means that the length of accurately placed rail to be laid is reduced by half. The three-mile instrument extends the concept further with eight aerials strung out over three miles. Four of the aerials -42 foot dishes-run on a three-quarter mile length of rail laid at the eastern extremity of the array to an accuracy better than one millimetre. The four similar fixed dishes are to be evenly spaced over the remainder of the three-mile system, and sixteen spacings will be available simultaneously. One twelve-hour run will be enough to plot a rough chart of the radio emission from an object, while eight runs will draw the complete map. But the complexity means that a computer is needed at the site- so far the punched tape output of the observatory's telescopes has been taken into Cambridge for processing at the university. The Myriad 2 computer which has been chosen will have a 30 inch line plotter to draw the maps, and will also control the eight telescopes.

When the three-mile telescope is built, the present one-mile instrument will be devoted largely to source counting. The view seems to be that most of the fainter sources have been seen, so that there is little point in looking back to even fainter sources. This is why it now seems more important to build an instrument for source mapping. The curious result is that the resolving powers of radio and optical telescopes are now rapidly converging.

\section{ARCHAEOLOGY}

\section{Ludgershall Custile}

\section{from our Archaeology Correspondent}

As the Ministry of Public Building and Works knows all too well, visitors who go out of their way to visit Ludgershall Castle in Wiltshire are apt to get annoyed when they discover that there is little to see above ground apart from the stump of a twelfth century tower. This is one reason why the ministry has financed a major excavation at the site, directed by Mr P. Addyman of the University of Southampton, during the past five seasons. There are, however, more academic justifications for the excavation. For one thing, from the beginning of the twelfth century until the fifteenth the castle was a royal residence and account books have survived, so there is an opportunity to correlate archaeological and documentary evidence. For another, Ludgershall in the twelfth century was a major ring-work castle, and only a few of them have been excavated. In fact the present day remains of the earthwork have an unusual figure of eight shape, which adds to the interest of the excavation.

The earlicst reference to Ludgershall Manor is in the Domesday Book. In 1086, it was owned by the Earl of Salisbury, but by 1103 it was in the hands of Henry I and it remained a royal residence until the fifteenth century, evolving in that time from a castle to a hunting lodge. The excavations have revealed no fewer than fifteen phases of construction as the buildings were repeatedly pulled down, rebuilt and extended, and these promise to give a detailed picture both of building

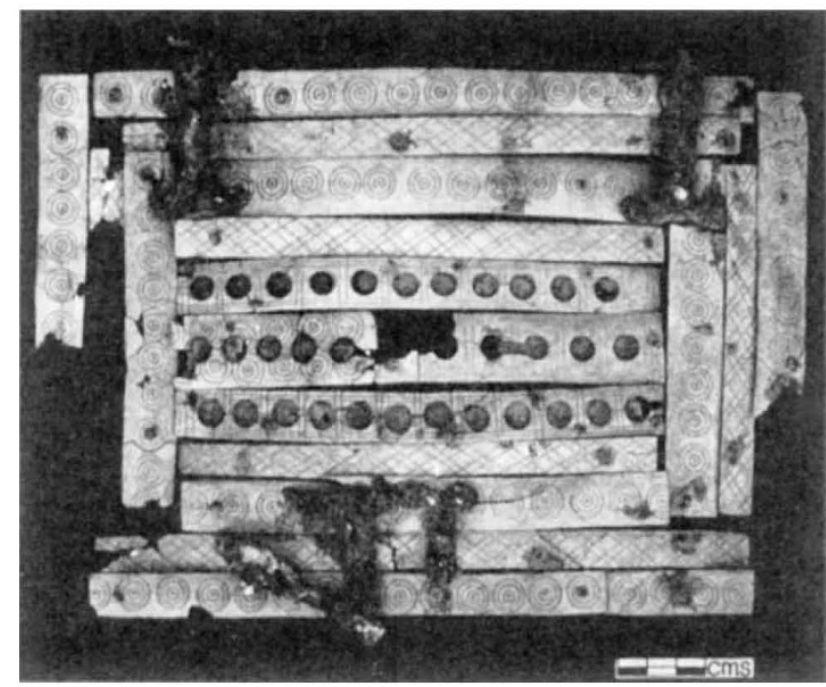

Bone strip decorations from the lid of a twelfth century casket discovered at Ludgershall Castle. The three central strips may have been inlaid with silver. The casket had two iron hinges and two iron hasps.

techniques and of the way of life in a royal household.

The figure of eight ring works, consisting of a ditch, a bank and an inner ditch, were built in two phases. The first fortification on the site, what is now the southern ring of the figure of eight, was built in the mid-twelfth century, perhaps by John the Marshall, who had a reputation for building castles "wonderous of devise", during the civil war between Stephen and Matilda. The northern loop of the figure of eight was added by Henry III. Originally the ditches were some twenty feet deep with very steep outer faces, and the banks were made of chalk revetted with timber.

In the twelfth century there were only wooden buildings in the southern ring, which can be securely dated by a coin of Stephen. Curiously enough, a large number of fox bones have been found, some of which show deficiency diseases; this raises the interesting possibility that foxes were being farmed at this time, presumably for their pelts. In the thirteenth and fourteenth centuries the area was redeveloped as servants' quarters. The wooden buildings were replaced with timber framed, flint walled houses and the large number of cattle bones indicates that their occupants had a comparatively simple diet.

The northern loop of the castle, by contrast, was developed into palatial royal quarters. During successive reigns, stone buildings of increasing sophistication were built there, and the defensive features of the castle, including the ditches, were progressively sacrificed for increased luxury as the castle evolved into a hunting lodge.

The architecture was of a standard fit for a cathedral, with intricately carved pillars, painted plaster walls and large windows. The royal buildings include a great hall, a solar-hall and kitchen range, sleeping chambers and a stone lined latrine; building materials include Cornish slate, Purbeck marble, Bath stone and stone from the Isle of Wight. As the contents of the latrine have shown, royal tastes in food matched those in architecture; literally thousands of quail and small bird bones have been found, as well as oyster shells, lobster shells and the bones of deer. 